HISTORIA: Jurnal Pendidik dan Peneliti Sejarah, 3(2), 135-144. DOI: https://doi.org/10.17509/historia.v3i2.23001.

Available online at HISTORIA; Jurnal Pendidik dan Peneliti Sejarah
Journal homepage: https://ejournal.upi.edu/index.php/historia

\title{
POTRET GERAKAN PEREMPUAN PADA ABAD KE 20 DI BATAVIA: POETRI MARDIKA 1912
}

\author{
Restu Diniyanti \\ Prodi. Sejarah dan Kebudayaan Islam, \\ Fakultas Adab dan Humaniora, UIN Syarif Hidayatullah Jakarta \\ restu_diniyanti18@mhs.uinjkt.ac.id
}

To cite this article: Diniyanti, R. (2020). Potret gerakan perempuan pada abad ke 20 di Batavia: Poetri mardika 1912. HISTORIA: Jurnal Pendidik dan Peneliti Sejarah, 3(2), 135-144. https://doi.org/10.17509/historia.v3i2.23001.

Naskah diterima : 23 Januari 2020, Naskah direvisi : 11 Mei 2020, Naskah disetujui : 4 Juli 2020

\begin{abstract}
Women's movements emerged in various parts of the world, including Indonesia. The women's movement existed because of the desire to make changes in women lives who are always portrayed in an oppressed position. This article discussed the women's movement in the early 20th century, which focused on improving social position as women in all aspects such as marriage and family, especially in the education aspect. The women's movement discussed in this article is the Poetri Mardika organization, the first organization existed in Batavia in 1912. This article analyzes how the women's movement emerged and what factors made women struggle to strengthen change, this was done using historical methods of analysis. This article found that the Poetri Mardika organization came from the idea that it was present in fighting for women's rights that was very important.
\end{abstract}

Keywords: national movement; Poetri Mardika; Soenting Melajoe; woman movement; woman organization.

\begin{abstract}
Abstrak
Gerakan perempuan muncul di berbagai dunia, diantaranya Indonesia. Gerakan perempuan hadir disebabkan adanya keinginan untuk melakukan perubahan dalam kehidupan para perempuan yang selalu digambarkan dengan posisi tertindas. Artikel ini akan membahas tentang gerakan perempuan yang hadir pada awal abad 20, dimana gerakan perempuan ini berfokus dalam peningkatan posisi sosial sebagai perempuan dalam segala aspek seperti aspek dalam perkawinan dan keluarga, terutama dalam aspek pendidikan. Gerakan perempuan yang akan dibahas dalam artikel ini adalah organisasi Poetri Mardika, organisasi pertama yang hadir di Batavia pada tahun 1912. Artikel ini menganalisa bagaimana gerakan perempuan muncul dan faktor apa yang membuat para perempuan berjibaku untuk memperkuat perubahan, hal ini dilakukan dengan menggunakan metode historis analisis. Artikel ini menemukan bahwa organisasi Poetri Mardika hadir berawal dari gagasan yang hadir dalam memperjuangkan hak perempuan itu sangat penting.
\end{abstract}

Kata Kunci: Gerakan perempuan; organisasi perempuan; pergerakan nasional; Poetri Mardika; Soenting Melajoe. 


\section{PENDAHULUAN}

Berbicara mengenai eksistensi perempuan di Indonesia kita tidak dapat memungkiri bahwa Perempuan Indonesia telah mengambil peran penting dalam perjuangan perjalanan bangsa yang tidak dapat dilupakan begitu saja. Eksistensi perempuan Indonesia dalam menentukan sejarah bangsa mengalami pasangsurut, kita dapat melihat dari mulai masa pendudukan bangsa Barat sampai awal kemerdekaan. Gerakan perempuan yang hadir di Indonesia tidaklah lahir begitu saja, akan tetapi dalam catatan sejarah dinamika gerakan perempuan hadir sangat erat kaitannya pada masa pergerakan nasional seperti lahirnya organisasi Boedi Oetomo, Indische Partij, Sarekat Islam dalam tahun 1908 sampai 1920 (Leirissa, 1989).

Pada masa kolonial perempuan telah mulai melakukan gerakan yang dilakukan oleh perorangan dan belum membentuk sebuah organisasi untuk membebaskan diri melalui gagasan-gagasannya, tokoh gerakan perempuan yang dianggap sebagai pelopor dari gerakan perempuan di Indonesia ialah R.A. Kartini (1879-1904). Perempuan Indonesia telah mengambil peran penting dalam perjuangan perjalanan bangsa yang tidak dapat dilupakan begitu saja. Bila diperhatikan awal tahun 1900-an merupakan sebuah tahun dimana semangat untuk memperbaiki keadaan perempuan mulai bangkit. Dalam kutipan surat kabar Soenting Melajoe yang di tulis oleh Hatidjah, ia menuliskan:

\section{Zaman ini diseboet orang zaman kemadjoean; madjoe! madjoe! apakah jang madjoe? dengan kata madjoe adalah soeatoe perkataan jang loeas mànanja. Madjoe dengan kata ma'na jang pantaslah saja oeraikan disini: Ditanah Europa dan Amerika soedah lama besar kemadjoean itoe hidoep hingga bertjabanglah di tanah Djepang dengan toemboehnja amat soeboer; madjoe di tempat jang terseboet itoe boekannja madjoe orang laki-laki sadja, tetapi sama sama madjoe dengan perempoean. Kita sama sama taoe bahwa di tanah Inggeris perempoean soedah mintak dengan keras akan disamakan hak laki-laki dengan hak perempoan (Hatidjah, 1913).}

Dalam kutipan tersebut dapat diasumsikan bahwa perempuan pada masa kolonial sudah mulai bergerak untuk memberikan kemajuan pada setiap perempuan, karena keadaan perempuan yang terbatas ruang geraknya sehingga menimbulkan adanya gagasan emansipasi terhadap perempuan yang mengidealkan kemajuan antara perempuan dan laki-laki harus sama. Gerakan perempuan berawal dilakukan dengan perorangan membuat para perempuan sadar bahwa peningkatan derajat kaum perempuan itu sangatlah penting, sehingga pada perkembangan selanjutnya perjuangan perempuan dilakukan dengan membentuk perkumpulan atau organisasi yang memiliki pandangan yang sama, yaitu untuk memajukan keadaan perempuan dari berbagai aspek, terutama dalam bidang pendidikan.

Periode ini merupakan suatu masa dimana bangsa Indonesia berjuang untuk melepas diri dari penjajah asing yang tidak lagi mengandalkan pada kekuatan senjata, melainkan dengan menggunakan suatu perkumpulan yang memiliki tujuan ataupun cita-cita yang sama: memajukan kesejahteraan bangsa (Suryochondro, 1984) dan bekerjasama dalam meraih tujuan guna mencapai cita-cita kemajuan diantaranya dengan membentuk sebuah organisasi (Wahyuningsih, 2013). Organisasi merupakan salah satu upaya untuk mencapai tujuan yang diharapkan lebih efisien, dikarenakan dalam sebuah organisasi setiap masingmasing anggotanya memiliki peran yang saling berkaitan dengan tujuannya. Kesadaran akan perlunya membentuk organisasi dalam mewujudkan cita-cita menyebabkan pula dalam periode ini disebut masa kebangkitan. Sebab, kunci perkembangan pada masa kebangkitan ini adalah dengan munculnya ide-ide baru mengenai organisasi dan dikenalnya gagasan baru (Ohorella, 1992).

Keterlibatan kaum perempuan pada abad ke-20 di mulai dengan berdirinya organisasi perempuan. Organisasi perempuan pada masa tersebut memiliki gagasan yang membuat kaum perempuan sadar bahwa peningkatan derajat untuk kaum perempuan sangatlah penting. Corak dari perkumpulan gerakan perempuan pada masa sebelum kemerdekaan bersifat fokus kepada perbaikan kedudukan perempuan hingga berkembang untuk meningkatkan hak pendidikan terhadap perempuan (Ohorella, 1992).

Pada tahun 1912 dibentuknya organisasi perempuan yang bernama Poetri Mardika, organisasi ini merupakan organisasi perempuan pertama di Batavia dan memiliki kontribusi yang cukup aktif dalam menggerakan memajukan taraf kehidupan perempuan dan Organisasi ini mendapatkan dukungan serta bantuan dari Budi Utomo yang menekankan pada bidang pendidikan serta kebudayaan (Vreede-de stuers, 2008).

Tokoh Poetri Mardika di antaranya: R.A. Theresia Saburudin, R.K. Rukmini, dan R.A. Sutinah Joyopranoto (Djoened dan Susanto, 1993)). Dalam majalah Poetri Mardika disebutkan bahwa pada tahun 1915, Teongkoe Theresia Saburudin sebagai ketua, R.Aj. S. Djajapranata sebagai wakil, Abdulrahman sebagai komisaris. Di dalam majalah Poetri Mardika tertulis sebutan untuk Theresia 
HISTORIA: Jurnal Pendidik dan Peneliti Sejarah, 3(2), 135-144. DOI: https://doi.org/10.17509/historia.v3i2.23001.

Sabarudin adalah Teongkoe, sedangkan dalam sumber buku lain sebutan untuk Theresia Saburudin adalah R.A.

Poetri Mardika merupakan organisasi yang bertujuan memberikan motivasi kepada perempuan pentingnya meningkatkan taraf hidup para perempuan baik dalam pendidikan maupun dalam kehidupan social (Suryochondro, 1984). Sesudah tahun 1912 jumlah perkumpulan perempuan bertambah banyak dan organisasi perempuan semakin luas orientasinya, terutama dalam menjangkau masyarakat bawah untuk mendapatkan kebebasan dalam kehidupan bermasyarakat.

Organisasi-organisasi besar pada masa itu juga mendirikan perkumpulanataubagiankhusus perempuan. Misalnya, Sarikat Islam, Muhammadiyah, dan Sarekat Ambon yang juga mempunyai kelompok pergerakan perempuan. Kelompok pergerakan perempuan dari Sarekat Islam ialah Wanudiyo Utomo kemudian Sarekat Perempuan Islam Indonesia (SPII), bagian perempuan dari Muhammadiyah adalah Aisyiyah, dan perkumpulan perempuan dari Sarekat Ambon adalah Ina Tuni.

Rata-rata perkumpulan-perkumpulan perempuan di atas bermaksud untuk memberikan kesempatan bagi perempuan memiliki kepandaian-kepandaian khusus, seperti keterampilan menjahit, membatik, merenda, dan sebagainya. Kegiatan ini diajarkan kepada perempuan agar mereka mempunyai kemampuan bertahan hidup tanpa selalu bergantung kepada laki-laki. Pergerakan perempuan 25 tahun pertama itu bersifat memperjuangkan nilai-nilai baru dalam hal pendidikan, kesusilaan, dan peri kemanusiaan, serta menuju pada usaha meninggikan kedudukan perempuan dalam keluarga dan masyarakat (Suryochondro, 1984).

Nampaknya hal ini sangat terkaitan dengan citacita organisasi Poetri Mardika. Kelahiran Poetri Mardika ini bertujuan memajukan pengajaran anak-anak perempuan, sekaligus memperjuangkan kemerdekaan untuk para perempuan. Lahirnya sebuah organisasi yang didorong oleh gagasan kemerdekaan menimbulkan kesadaran butuhnya untuk menyebarkan suara mereka secara luas dengan melalui media massa. Media massa dianggap sebagai kebutuhan untuk menampung maksud tersebut (Junaedhi, 1995).

Menurut Myra M. Sidharta di dalam buku yang di tulis oleh Junaedhi (1995) bahwa surat kabar perempuan pertama adalah Tiong Hwa Wi Sien Po yang di urus oleh Lien Titie Nio dan surat kabar kedua adalah Poetri Hindia yang terbit pada 1908 yang di pimpin oleh RTA Tirtokoesomoe, dan pada tahun 1912 dari Sumatra Barat menerbitkan surat kabar yang bernama Soenting Melajoe (Junaedhi, 1995). Begitupun dengan Poetri Mardika yang mengeluarkan surat kabar untuk menyebarluaskan gagasan-gagasan mereka. Surat kabar Poetri Mardika di terbitkan mulai tahun 1915, dengan semboyan surat kabarnya yaitu "soerat kabar memperhatikan keadaanja pihak perempoan boemi poetra di Insulinde", di dalam surat kabar tersebut berisikan pengajaran terhadap perempuan serta gagasan-gagasan baru untuk para perempuan (Junaedhi, 1995). Surat kabar Poetri Mardika tercantum nama percetakannya yaitu NV. Drukkerij Boedi Oetomo Surakarta (Junaedhi, 1995). Surat kabar ini mengandalkan pembiayaanya dari pelanggannya, lihat warta redactie dalam surat kabar Poetri Mardika berikut ini:

Dari sebab kekoerangan wang, maka soerat kabar Poetri Mardika ini tjoema di keloearkan 8 katja. Menoeroet perhitoengannja Administratie, maka soerat kabar Poetri Mardika bisa djoega dikeloerkan 12 katja djikalaoe tida ada langganan jang menoenggak. Maka dari itoe kami harap pertolongannja langganan-langganan, soepaja kami bisa mengeloerkan soerat kabar Poetri Mardika sebagaimana biasa (Poetri Mardika, No.4, Juli 1915).

Media massa tentunya sangat berpengaruh terhadap organisasi Poetri Mardika. Poetri Mardika berperan sebagai pewacana emansipasi perempuan dengan memperkenalkan gagasannya melalui surat kabar misalnya, dalam persoalan pendidikan untuk perempuan. Di dalam sebagian surat kabar secara jelas dituliskan bahwa Poetri Mardika membantu meningkatkan pendidikan perempuan dengan memberikan bantuan dana beasiswa pendidikan serta memberikan pengajaran dan kesadaran akan pentingnya meraih kemajuan terhadap perempuan terutama dalam bidang pendidikan. Tujuan utama Poetri Mardika memberikan pengajaran kepada kalangan perempuan karena masih sangat kurangnya sekolah-sekolah untuk perempuan pribumi, disamping itu adat maupun kebiasaan yang dapat dikatakan menghambat kemajuan perempuan, seperti praktik pernikahan usia dini, praktik kawin paksa dan lain-lain.

Meskipun organisasi ini tidak berdiri lama namun dampaknya sangat besar dengan adanya berbagai perkumpulan perempuan lain, baik yang didukung oleh organisasi-organisasi umum laki-laki, maupun yang terbentuk secara mandiri oleh kaum perempuan itu sendiri. Kesediaan perempuan untuk terlibat dalam kegiatan organisasi makin meningkat dan kecakapan berorganisasi pun bertambah maju. Hal ini disebabkan karena kesempatan belajar makin meluas dan 
berkembang ke lapisan bawah. Contoh peran nyata yang telah diupayakan oleh Poetri Mardika tercantum dalam verslag Poetri Mardika No. 5 Agustus 1915 ditulis oleh Sadikoen Toendoekoesomo mengatakan bahwa Poetri Mardika telah membiayai dua anak perempuan di HBS, satu anak perempuan di sekolah Belanda, tiga anak di Bataviasche Kartinischool, dan satu anak perempuan di sekolah swasta.

\section{PEMBAHASAN}

Artikel ini akan menjelaskan terkait perkembangan serta pertumbuhan organisasi Poetri Mardika yang di dalamnya memperlihatkan dinamika organisasi serta gerakan emansipasi perempuan yang telah di propagandakan. Bagian dalam pembahasan ini berisi tentang peran serta kontribusi Poetri Mardika, hal ini di lihat dari pergerakan perempuan di Hindia Belanda pada awal abad ke-20.

\section{Hadirnya Organisasi Poetri Mardika}

Gerakan perempuan yang muncul di abad ke-20 bersifat mengutamakan perubahan keadaan sosial. Secara umum, gerakan perempuan hadir di karenakan adanya perubahan sosial yang terjadi dalam masyarakat (Syani, 1995). Hal ini di sebabkan beberapa faktor, di antaranya adalah: adanya keinginan untuk melakukan perubahan yang merupakan hasil gagasan para intelektual dalam masyarakat dengan berstandar pada tujuan-tujuan dan kehendak-kehendak tertentu, sehingga menimbulkan perubahan sosial yang salah satunya berdampak pada muncul di antaranya gerakan perempuan (Suhartono, 1994). Pada abad ke20 perempuan lebih banyak berupaya dalam perbaikan kedudukan sosial, peningkatan kemampuan melalui pendidikan serta mempertinggi keterampilan sebagai seorang ibu.

Perkumpulan perempuan pertama yang berdiri di kota Batavia adalah Poetri Mardika pada tahun 1912. Poetri Mardika mencita-citakan kemajuan terhadap perempuanagartidaklagimenjadiperempuanyanghanya terpaku mengikuti adat istiadat saja, melainkan sebagai perempuan diharuskan aktif dalam meningkatkkan derajat mereka. Berikut ini kutipan dalam surat kabar yang ditulis oleh Rahardjo mengenai kemajuan yang dicita-citaka oleh Poetri Mardika;“...Adapoen maksoed kemadjoewan itoe kalau tiada salah, jaitoe: menoentoet segala kepandaian kala bisa menoentoet kepandaiannja lain bangsa, setidak-tidaknnja sendiri bisa sempoerna soedah baik dan bagoes" (Rahardjo, 1917).
Jelas sekali bahwa Poetri Mardika memang memperjuangkan kemajuan untuk perempuan dan meningkatkan kualitas diri para perempuan. Poetri Mardika bukan organisasi perempuan yang berasaskan Islam, organisasi ini terbuka untuk agama apapun karena tujuan dari organisasi ini adalah kemajuan untuk seluruh para perempuan. Tertulis dalam surat kabar Poetri Mardika sebagai berikut:

Njatalah bahwa kamardikaan tida tjoema kita jang mengharap tetapi djoega lain-lain orang. Baik jang beragama Islam, baik jang beragama Christen, maoepoen jang memeloek agamanja nabi Kong oe Tjoe, bagi saja terang sekali boleh kita pertjaja, jang kamardikaan itu boekan sekali-sekali kehendaknja Agama, sebagaimana kebanjakan poenja kira kalau maonja agama Christen, tetapi memang haknja manoesia boeat memegang tetap kemanoesiaanja. Jaitoe kamardikaan menjadi sendjata, boeat menjampoernakan oetamanja hidoep penghidoepan kita. Mardika lepas dari rintangan, baik rintangan lahir maopoen rintangan batin (Koesomo, 1917)

Kutipan di atas menunjukan bahwa organisasi Poetri Mardika memang bertujuan memajukan kaum perempuan tanpa melihat atau memandang agama, karena bagi Poetri Mardika bahwa kemerdekaan adalah hak semua orang, seperti penjelasan sebelumnya bahwa Poetri Mardika berdiri karena bertujuan untuk meningkatkan kemajuan serta membebaskan diri dari adat istiadat yang menghambat kemajuan bukan berarti untuk mencoba menghilangkan adat istiadat. Dalam kutipan surat kabar Poetri Mardika bahwa R.Ng Asiah (R.Ng. Asiah adalah ketua organisasi Poetri Mardika pada masa kepemimpinan tahun 1916-1919) mencoba untuk menerangkan maksud dari pembentukannya Poetri Mardika agar masyarakat tidak salah paham ketika mengeluarkan gagasannya tentang kemerdekaan tersebut:

"...P.M. tidak sekali-kali berkehendak menghilangkan adat-istiadat, adat jang maka kematiannja pehak perempoean kepada pehak lelaki dan pada maatschapphy, sebab adat lembaga itoe MEMANG PERLOE dan kalau dihilangkan nistjaja membinasakan bangsa. Hal perobahan adat istiadat itoe, tergantoeng atas keperloewannja (keboetoehanja). Djadi tidak benar sekali kalau arti MERDEKA (jang berarti loewes) diartikan memboewang2 adat istiadat. Pendek kata: MERDEKA, kalau diartikan LOSBANDIGHEID itoe salah jang besar, dan besarnja mesti diartikan loewes (Verslaag Algemenee Vergadering P.M. di gedoeng No. 41 KRAMAT (Weltevderen) pada tanggal 19

HISTORIA: Jurnal Pendidik dan Peneliti Sejarah, p-issn:2620-4789 | e-issn:2615-7993 
HISTORIA: Jurnal Pendidik dan Peneliti Sejarah, 3(2), 135-144. DOI: https://doi.org/10.17509/historia.v3i2.23001.

Agustus 1917, dalam surat kabar Poetri Mardika, Oktober, 1917, No 10, Tahun IV)

Kutipan di atas menunjukan bahwa Poetri Mardika mencoba untuk membebaskan perempuan agar lebih terbuka ruang geraknya yang selama ini terbelenggu oleh adat istiadat seperti pernikahan usia dini, larangan akan meraih pendidikan di sekolah, dan sebagaimana yang telah di sebutkan pada bab sebelumnya. Poetri Mardika hanya bermaksud untuk mencoba menghilangkan adat istiadat yang di anggap perlu di hilangkan dan dapat menghambat kemajuan perempuan dalam hal pendidikan, seperti pernikahan usia dini, pelarangan perempuan untuk sekolah, dan tradisi pergundikan.

Selanjutnya ketika menjadi organisasi pertama tentu saja terdapat upaya yang mesti dilakukan oleh Poetri Mardika beberapa diantaranya adalah: Pertama, peran Poetri Mardika adalah memberikan wacana emansipasi perempuan yang di gulirkan melalui surat kabar. Menerbitkan surat kabar yang merupakan isi dari gagasan mereka adalah sebagai sarana untuk memberikan pendidikan dan pengajaran. Poetri Mardika mengeluarkan surat kabar yang berasal dari pikiran atau persepsi para anggotanya, karena Poetri Mardika mewajibkan di setiap anggota untuk menuangkan tulisan mereka yang berisi pikiran, perasaan ataupun kegelisahan mereka. Alasan Poetri Mardika mewajibkan setiap anggota untuk membuat artikel agar masingmasing dari anggota dapat menuangkan isi hati mereka ataupun gagasan mereka, yang kemudian akan dirundingkan untuk mencari solusi ataupun informasi bagi setiap orang (Sadikoen, 1915. hlm. 63). Tulisan yang tercantum dalam surat kabar Poetri Mardika berisi pengajaran agar perempuan cakap dalam mengurus rumah tangga, informasi tentang pendidikan serta memberikan informasi kegiatan Poetri Mardika.

Surat kabar Poetri Mardika juga banyak memuat tulisan darilaki-laki yang mendukung wacana emansipasi terhadap perempuan adalah surat kabar Poetri Mardika. Hal ini menunjukkan terhadap pembacanya, sebagian laki-laki pun sudah berfikiran maju dan menginginkan perempuan menjadi lebih baik meskipun sebagian besar masih banyak masyarakat melekat pikiran negatif bahwa jika perempuan telah pandai akan merasa tinggi dan tidak hormat terhadap laki-laki (Koesomo, 1916, hlm. 54).

Kedua, peran Poetri Mardika selanjutnya adalah memberikan beasiswa. Poetri Mardika merupakan gerakan perempuan yang berupaya untuk memperbaiki keadaan pendidikan terhadap perempuan. Perjuangan organisasi ini sangat jelas, yaitu memberikan beasiswa terhadap anak-anak yang kurang pendidikan terkhususnya anak perempuan. Di gambarkan dalam kutipan mengenai pandangan dari R.A. Kartini bahwa:

"...Pendidikan itu harusnya bersifat nondiskriminatif karena setiap orang berhak untuk belajar mengembangkan diri mereka, selain itu juga pendidikan yang harus diberikan selain dari pengetahuan dan keterampilan adalah pendidikan karakter karena dengan kepribadianlah yang dapat menentukan kualitas suatu bangsa..." (Soeratman, 1979).

Pandangan serta gagasan dari R.A. Kartini telah menjadikan acuan visi dan misi organisasi Poetri Mardika dalam hal pendidikan. Alasan perempuan menuntut hak untuk mendapatkan pendidikan itu dikarenakan perempuan pada masa kolonial tidak mendapatkan keadilan yang layak. Maka dari itu pendidikan merupakan salah satu upaya untuk mengangkat derajat para perempuan dan melepaskan mereka dari kegiataan adat-istiadat yang merugikan pihak perempuan. Maka Poetri Mardika memperjuangkan pendidikan dengan memberikan bantuan dana kepada perempuan agar dapat bersekolah (Vreede-de stuers, 2008). Lihat dalam lampiran terdapat tabel jumlah anak-anak yang ditanggung oleh Poetri Mardika. Dalam tabel yang disebutkan merupakan bagian bukti nyata bahwa Poetri Mardika pendekatannya sangat kongkrit dengan mengupayakan memberikan bantuan terhadap para anak perempuan agar dapat mengenyam pendidikan.

Pada tahun 1915 Poetri Mardika membiayai sekitar tujuh orang anak, 1916 terdapat tujuh orang anak, 1917 terdapat sembilan orang anak, 1918 terdapat sembilan orang anak dan pada tahun 1919 enam orang anak. Berkurangnya anak tanggungan Poetri Mardika karena ada yang melanjutkan ke MULO secara gratis, ada yang memutuskan untuk berhenti dan menikah (Kadiroen, 1920a, hlm.7). Poetri Mardika merupakan organisasi yang memiliki dana cukup besar, karena setiap anggota Poetri Mardika di wajibkan untuk membayar iuran perbulannya, hanya saja tidak disebutkan nominal dana iuran tersebut.

Poetri Mardika juga mendapatkan uang donasi, sehingga dapat memberikan beasiswa kepada anak-anak terutama perempuan yang membutuhkan pendidikan (Sadikoen, 1916, hlm. 17). Dana tersebut digunakan untuk biaya keperluan anak-anak tanggungan Poetri Mardika dan untuk biaya operasional. Kemungkinan anggota Poetri Mardika merupakan kumpulan dari golongan atas dengan merujuk lampiran daftar namanama anggota Poetri Mardika yang menandakan namanama para bangsawan. 
Dalam majalah Poetri Mardika terdapat laporan bahwa mereka menerima dua anak murid kartini di Batavia pada bulan juli 1915 (Djojopranoto \& Sadikoen, 1915, hlm.8), kemudian pada bulan agustus tahun 1916, Poetri Mardika telah memberikan beasiswa kepada dua anak perempuan disekolah H.B.S, satu anak di Semarang, satu anak di Batavia, satu anak perempuan di sekolah Belanda gouverment, tiga anak perempuan di Bataviasche kartini school dan satu anak sekolah swasta (Sadikoen, 1916).

Poetri Mardika merupakan organisasi netral terhadap agama, namun anggota Poetri Mardika realitanya mayoritas beragama Islam, dengan ini Poetri Mardika mengupayakan untuk mengkampanyekan wacana untuk para siswa agar memperoleh pendidikan Islam di sekolah. Hal ini merupakan upaya yang cukup unik bagi penulis karena, organisasi ini tidak berasaskan Islam dan terbuka untuk umum (tidak menutup diri dari perbedaan agama) namun, Poetri Mardika tetap memperjuangkan Islam. Salah satu contoh di dalam surat kabar Poetri Mardika di tuliskan bahwa, organisasi Poetri Mardika sangat mengharapkan pengadaan pendidikan agama Islam di sekolah-sekolah terutama di K.T.S (Kartini School) serta menyediakan guru Agama Islam, karena pengajaran Agama Islam cukup sulit bila diajarkan di luar sekolah. Hal ini disebabkan karena:

a)Oerang toeanja masih tiada sempat memberi pengadjaran, atau meskipoen sempat tiada sampoerna hal itoe, b) di kampoeng djarang ada goeroe goeroe memberi pengadjaran, ja ada joega akan tetapi hanja di adjar mendjadi Koran sadja lain lain tiada, c) oempama meskipoen dikampoeng ada goeroe mengadjar Igama, toch misti mengeloearkan ongkos lagi. Demikian joega berat jang akan beladjar, mana tempo goena belajar pagi, mana tempo goena belajar agama (Tjipto, 1916, hlm. 108).

Usaha ini telah menunjukan bahwa meskipun organisasi ini terbuka untuk umum dan bukan organisasi Islam namun, organisasi Poetri Mardika tetap memperjuangkan Islam.

Ketiga, organisasi Poetri Mardika merupakan penggerak utama organisasi perempuan yang dapat menyebarkan pandangan progresif tentang emansisapasi dan terbukti menjadi organisasi pertama karena telah memberikan wacana emansipasi yang berdampak besar terhadap perempuan lainnya. Organisasi Poetri Mardika dapat dikatakan cukup berperan penting karena Poetri Mardika menjadi salah satu organisasi yang terkemuka dimasanya, dapat dilihat keaktifannya dengan melalui aktivitas propoganda yang dilakukan (Poetri Mardika, 1915).

Poetri Mardika juga merupakan organisasi yang dapat berkembang cepat di karenakan pergerakannya berada di Batavia yang merupakan salah satu kota yang berkembang di Hindia Belanda. Di Batavia terdapat banyak sekolah, pusat kesehatan, dan pusat pemerintahan yang didirikan di kota ini dan Batavia merupakan sebagai pusat pendidikan terbesar karena banyaknya lembaga-lembaga pendidikan menengah dan tinggi (Blackburn, 2012). Poetri Mardika organisasi yang cukup tinggi kepopularitasnya dikarenakan Poetri Mardika seringkali menyebarkan propaganda di berbagai daerah di Indonesia terutama di Jawa. Poetri Mardika mengadakan propaganda (acara ini seperti acara kongres) di wilayah Buitenzorg pada 6 Juni 1916 dengan bantuan dari perhimpunan Harso Darsino (Djojopranoto \& Sadikoen, 1915).

Poetri Mardika juga mengadakan acara propaganda yang diadakan di daerah Madiun (11 Juli 1915) dan Surabaya (18 Juli 1915). Adapun tujuan kegiatan kegiatan propaganda ini semata-mata untuk memperkuat serta memajukan perhimpunan perempuan agar memiliki banyak relasi serta memberikan pengajaran melalui acara ini. Kegiatan propaganda ini menghasilkan pengadaan kerja sama antara Poetri Mardika dengan para nyonya Belanda untuk mendirikan kongres perempuan hal ini berupaya untuk menguatkan serta memperkenalkan perhimpunan Poetri Mardika ke berbagai pelosok Indonesia (Djojopranoto \& Sadikoen, 1915). Kemudian dalam laporan surat kabar Poetri Mardika di katakan bahwa Poetri Mardika telah masuk menjadi bagian dari anggota Nederlandsh Indisch Kongres Voor Opvoeding En Onderwijs (NIOK):

Moelai dalam tahoen 1918 maka kita empoenja perhimpoenan masoek mendjadi anggota dari Ned. Ind. Kongres v. Opvoending en Onderwijs. Kami merasa perloe dan faedah tjampoernja Poetri-Merdika dengan perhimpoenan ini jang bermaksoed memperbaiki adanja pengadjaran oentoek kita ampoenja anak-anak, karena kita sendiri menganggep onderwijs soatoe alat jang teroetama goena mendjoendjoeng deradjatnja fehak perempoean (Kadiroen, 1920b, hlm. 8).

Laporan diatas telah menunjukan bahwa Poetri Mardika memperkuat organisasinya dengan cara bergabung dengan perhimpunan-perhimpunan yang lain. Melihat upaya-upaya Poetri Mardika berjuang untuk meraih cita-citanya tersebut, tidak heran sehingga Poetri Mardika menjadi organisasi yang terkemuka. Dalam 
HISTORIA: Jurnal Pendidik dan Peneliti Sejarah, 3(2), 135-144. DOI: https://doi.org/10.17509/historia.v3i2.23001.

sebuah berita tentang kegiatan propaganda organisasi yang dilaporkan di surat kabar.

\section{Upaya - Upaya Organisasi Poetri Mardika}

Dampak dari perjuangan Poetri Mardika diantaranya adalah mulai terbukanya akses pendidikan bagi kaum perempuan. Akses pendidikan bagi kaum perempuan dari tahun ke tahun telah memberikan bukti bahwa perempuan Indonesia tidak hanya di jadikan dan dipandang sebagai kaum yang rendah saja. Perempuan juga mampu merubah kehidupannya menjadi lebih baik dengan mendapatkan hak pendidikannya yang sama seperti dengan kaum laki-laki. Pemerintah kolonial juga sudah banyak mendirikan sekolah-sekolah untuk kaum perempuan Indonesia.

Mereka sadar bahwa pendidikan juga perlu diberikan kepada kaum perempuan. Sekolah-sekolah khusus bagi kaum perempuan secara lambat laun bermunculan, salah satu contohnya adalah Kartini Fonds yang didirikan pada tahun 1913 yang menjadikan perempuan mendapatkan pendidikan dan menjadi lebih maju. Pada tahun 1918, pemerintah juga mendirikan sebuah Sekolah Guru (Kweekschool) untuk guru-guru perempuan di Salatiga. Guru-guru lulusan ini berhak untuk mengajar di HIS (Hollands Inlandse School) dan juga di Kartini Fonds (Cahyani, Swastika, \& Sumarjono, 2014). Di bawah ini merupakan tabel laporan pemerintah tentang pendidikan kejuruan di tahun 1928 semakin meningkat terutama perempuan.

Laporan dinas pendidikan menyatakan bahwa 58 persen dari perempuan Indonesia berhasil meraih ijazahnya pada 1928 (Vreede-de stuers, 2008). Penulis hanya memberikan gambaran bagaimana keadaan pendidikan yang di dapatkan oleh perempuan setelah hadirnya organisasi Poetri Mardika. Poetri Mardika telah memberikan pengaruh terhadap perempuan agar lebih mudah dalam mengakses pendidikannya. Selanjutnya dampak dari perjuangan Poetri Mardika ialah munculnya perhimpunan-perhimpunan perempuan baru di daerah-daerah lainnya dengan tujuan yang sama, seperti Kautaman Istri, Pengasah Budi, Poernahma Sidhi yang mana juga memiliki tujuan untuk memperhatikan keadaan perempuan (Sadikoen, 1916). Hal ini dikarenakan Poetri Mardika selalu melakukan propaganda ataupun kongres-kongres di berbagai daerah dengan tujuan memperkenalkan perhimpunannya dan menguatkan relasinya dengan perhimpunan yang lain. Terselenggaranya Kongres Perempuan Pertama di Yogyakarta Tahun 1928 kemungkinan besar pengaruh atau dampak dari munculnya organisasi Poetri Mardika yang merupakan salah satu penggagas kemerdekaan perempuan. Pesan dan keputusan Kongres itu pada dasarnya sama dengan yang diperjuangkan dan dikampanyekan oleh Poetri Mardika sejak berdirinya di tahun 1912.

Dalam acara kongres Perempuan yang pertama di selenggarakan memanglah tidak dijelaskan bahwa Poetri Mardika mengikuti kongres tersebut, dari berbagai utusan organisasi perempuan sekitar ada 22 organisasi perempuan. Adapun hasil lain dari adanya kongres ini yakni diputuskan hendak mengadakan studiefonds (dana beasiswa) untuk anak-anak gadis yang pandai tetapi tidak mampu. Selain itu kongres berkeputusan untuk mencegah perkawinan anak-anak dengan cara tiap anggota harus membuat propaganda tentang buruknya perkawinan anak-anak Kongres juga mengirimkan pesan kepada Pemerintah Hindia Belanda agar secepatnya diadakan tunjangan bagi janda dan anak-anak. Memang sulit diketahui dengan tepat berapa banyak organisasi perempuan di Hindia-Belanda yang aktif pada saat itu dan organisasi mana yang tidak terwakili dalam kongres.

Walaupun dapat ditemukan data mengenai pembentukan organisasi yang lumayan banyak di seluruh kepulauan Indonesia, namun kebanyakan organisasi tersebut pendek umurnya dan sering kali tidak tercatat kapan sebuah organisasi menghentikan kegiatannya atau bahkan bubar (Blackburn, 2007). Begitupun dengan Poetri Mardika, tidak adanya kejelasan organisasi Poetri Mardika menghentikan kegiataannya. Sesudah tahun 1920, jumlah organisasi perempuan bertambah banyak. Kesediaan kaum perempuan untuk terlibat dalam kegiatan organisasi lebih meningkat dan kecakapan bertindak dalam organisasi pun bertambah maju. Hampir di semua tempat yang penting ada perkumpulan perempuan. Hal ini disebabkan karena kesempatan belajar yang makin berkembang ke bawah, sehingga jumlah perempuan yang mampu beraksi juga bertambah luas dan tidak lagi terbatas pada lapisan atas saja.

\section{SIMPULAN}

Poetri Mardika adalah organisasi perempuan yang berdiri pada tahun 1912 di Batavia yang bertujuan untuk memperjuangkan perempuan agar mendapatkan hak-hak mereka meraih pendidikan serta meningkatkan kualitas perempuan dalam perbaikan kehidupanberkeluarga, perkawinan, dan mempertinggi usaha-usaha untuk mencapai kesejahteraan. Munculnya Poetri Mardika merupakan faktor dari adanya pandangan baru atas kesadaran terhadap perempuan. Para anggota Poetri Mardika yang aktif mayoritas dari golongan 
terpelajar ningrat. Organisasi ini merupakan organisasi yang berpusat di kota Batavia yang dimana kota tersebut telah menjadi pusat perkembangan kegiatan masyarakat. Apa yang dilakukan oleh organisasi Poetri Mardika merupakan upaya gerakan emansipasi perempuan yang bertujuan untuk mempertinggi nasib dan derajat para perempuan. Sisi lain keunikan dari Poetri Mardika ialah organisasi yang meskipun bebas dan terbuka untuk umum, namun organisasi ini tidak lupa memperjuangkan Islam dengan mengkampanyekan bahwa pendidikan Agama Islam harus diadakan di sekolah-sekolah.

Adapun peran maupun kontribusi Poetri Mardika adalah sebagai berikut:

1. Poetri Mardika menjadi inisiator bagi organisasi perempuan lainnya yang hadir setelah Poetri Mardika. Organisasi ini juga melakukan sosialisasi dengan mengadakan kegiatan kongres-kongres di berbagai daerah sehingga menjadikan Poetri Mardika semakin kuat jaringannya dengan perhimpunan-perhimpunan lainnya.

2. Poetri Mardika berupaya memberikan pengajaran kepada masyarakat luas, terutama perempuan, yang dapat membangkitkan semangat pembaruan, keterbukaan, dan nasionalisme melalui surat kabar yang diterbitkannya. Surat kabar ini berfungsi sebagai penyebar gagasan kemajuan perempuan sekaligus menjadi sarana yang memudahkan para perempuan ataupun masyarakat lainnya dalam mentransmisikan misi-misi Poetri Mardika. Surat kabar yang terbit pada tahun 1900-an ini juga berperan aktif sebagai media sosialisasi Poetri Mardika kepada masyarakat. Dalam surat kabar tersebut, misalnya berisi salah satu bentuk dukungan bagi perempuan untuk mendapatkan pendidikan serta pentingnya pendidikan bagi kaum perempuan, masalah pendidikan campuran antara laki-laki dan perempuan, serta pemberian kelonggaran untuk bergerak bagi kaum perempuan di tengah era Kolonialisme Belanda.

3. Poetri Mardika mencoba untuk menanamkan kesadaran terhadap perempuan dalam meraih pendidikan contohnya adalah para anggota Poetri Mardika itu sendiri yang kerapkali mendongkrak wacana akan pentingnya pendidikan di tengah masyarakat. Alasan utama atau alasan pokok kaum perempuan ingin mendapatkan pendidikan yang setara dengan laki-laki tidak lain adalah kaum perempuan Indonesia pada masa kolonial Belanda tidak diperlakukan adil untuk mengekspresikan diri mereka dalam menerima pendidikan.

4. Poetri Mardika meningkatkan upaya penegakan keadilan serta hak asasi perempuan dalam kehidupan. Hal ini dilakukan dengan cara membantu para perempuan untuk keluar dari kungkungan adat seperti poligami, pernikahan anak di bawah umur, sistem nyai, sistem selir, ataupun kawin paksa. Kemudian Poetri Mardika mengupayakan pengadaan kegiatan dana pensiun untuk para jandajanda. Hal ini menjadi salah satu bukti bahwa Poetri Mardika berperan aktif terhadap perempuan dan kuat dengan tujuannya yang ingin meningkatkan taraf hidup perempuan. Poetri Mardika adalah organisasi yang terbuka untuk umum. Maksudnya organisasi ini tidak menutup peluang bagi orang yang berbeda ras, suku, agama serta negara. Namun demikian anggotanya adalah beragama Islam. Kemudian hambatan yang dialami oleh organisasi Poetri Mardika dapat terjadi dikarenakan kurangnya pemasukan dana serta merosotnya aktivitasaktivitas oragnisasi yang kerap kontributif untuk mengadakan kegiatan dan menulis artikel. Hal ini disebabkan banyaknya kepentingan-kepentingan lainnya disetiap urusan para anggota. Faktor lainnya yang menyebabkan organisasi ini pudar cahayanya adalah masifnya resintesi-resintesi yang berasal dari masyarakat yang menolak perubahan. Dapat dikatakan juga bahwa awal abad ke-20 merupakan abad fase dasar perjuangan hak-hak perempuan Indonesia. Kemudian dampak yang terjadi terhadap perempuan dengan hadirnya Poetri Mardika adalah membuka pikiran yang membelenggu akan adat isitiadat yang merugikan pihak kaum perempuan. Sekolah-sekolah bagi kaum perempuan secara bertahap telah didirikan. Kaum perempuan sudah banyak yang bersekolah, mendapatkan pendidikan yang selayaknya, perempuan menjadi lebih maju dan pendidikan sudah dibuka bagi kaum perempuan. Selain itu secara lambat laun keadaan lekas berubah menjadi lebih baik dari tahun ke tahun, misalnya poligami, kawin paksaan, berlakunya kekuasaan suami yang tidak terbatas terhadap perceraian, membiarkan gadis-gadis bodoh akibat larangan untuk bersekolah setelah mulai dewasa, perkawinan anak-anak dan permasalahan perempuan lainnya sudah mulai berkurang. Perempuan secara lambat laun telah mampu untuk bangkit dalam menghilangkan kebijakan pemerintah kolonial yang telah membatasi akses pendidikan bagi kaum perempuan dan kekangan adat istiadat, mereka berjuang demi mendapatkan pendidikan agar tidak selalu dipandang lemah dalam segala hal. Maka organisasi Poetri Mardika telah membuat perempuan Indonesia menjadi maju serta mampu berperan aktif dalam pergaulan nasional bahkan

HISTORIA: Jurnal Pendidik dan Peneliti Sejarah, p-issn:2620-4789 | e-issn:2615-7993 
HISTORIA: Jurnal Pendidik dan Peneliti Sejarah, 3(2), 135-144. DOI: https://doi.org/10.17509/historia.v3i2.23001.

Internasional dengan segala upaya yang telah dilakukannya.

\section{REFERENSI}

Blackburn, S. (2007). Kongres perempuan pertama tinjauan ulang. Jakarta: Yayasan Obor Jakarta/ Jakarta- KITLV.

Blackburn, S.(2012). Jakarta sejarah 400 tahun. Jakarta: Masup Jakarta.

Cahyani, S.T.F. Swastika, K., \& Sumarjono (2014). Perjuangan organisasi perempuan Indonesia menuntut hak pendidikan pada masa kolonial Belanda tahun 1912-1928. Artikel Ilmiah Mahasiswa, I(1), 1-14.

Djoened, M. P dan Susanto, N. (1993). Sejarah nasional Indonesia $V$. Jakarta: Balai Pustaka.

Djojopranoto, S., \& Sadikoen. (1915, November). Verslag P.M. dalem boelan juli sampai September 1915. Poetri Mardika, 2(8), 80.

Hatidjah. (1913, Desember). Geraknja Kaoem Moeda Perempoan. Soerat Kabar Soenting Melajoe, 2(51).

Junaedhi, K. (1995). Rahasia dapur majalah di indonesia. Jakarta: PT Gramedia Utama.

Kadiroen. (1920a). Hal anak-anak jang menjadi tanggoengan P.M. Extra Nummer 1920, h. 7.

Kadiroen. (1920b). Nederlandsh indisch kongres voor opvoeding en onderwijs. Extra Nummer 1920, h. 8.

Koesomo, S. (1917, Maret). Perampoean boemipoetra dibitjarakan. Poetri Mardika. 4(3), 29.

Koesomo, S. (1916, Mei). Maksoed dan keandaanja Perobahan Alam Perempoan. Poetri Mardika, 3(5), 54.
Leirissa, R.Z. (1989). Pemikiran tentang sumpah pemuda. Jakarta: ISDN.

Ohorella, G.A. Dkk. (1992). Peranan wanita Indonesia dalam pergerakan nasional. Jakarta: Departemen Pendidikan dan Kebudayaan.

Poetri Mardika, No.4/ II, Juli 1915.

Poetri Mardika, Oktober, 1917, No 10, (Tahun IV).

Rahardjo. (1917, Oktober). Wellevenbeid bagian I. Poetri Mardika, 4(10), 103.

Sadikoen. (1915, September). Perobahan Alam Perempoan. Poetri Mardika, 2(6), 63.

Sadikoen. (Februari. 1916). Peritoengan wang kas P.M. dalem boelan October $\mathrm{t} / \mathrm{m}$ December 1915. Poetri Mardika. h. 17.

Suhartono. (1994). Sejarah pergerakan nasional: dari budi utomo sampai proklamasi 1908-1945. Yogyakarta: Pustaka Pelajar.

Suryochondro, S. (1984). Potret pergerakan wanita di indonesia. Jakarta: CV Rajawali.

Soeratman, Ki. (1979). Kartini dan pendidikan: Satu abad kartini. Jakarta: Sinar Harapan.

Syani, A. (1995). Sosiologi dan perubahan masyarakat. Unila Bandar lampung: Pustaka Jaya.

Tjipto. (1916, Oktober). K.T.S dan agama islam. Poetri Mardika, 3(10), 108.

Wahyuningsih, F. (2013). Perjuangan tokoh emansipasi perempuan Indonesia dan Jerman. Lentera Jurnal Studi Perempuan, 9(1).

Vreede-de stuers, C. (2008). Sejarah perempuan Indonesia gerakan \& pencapaian. Jakarta: Komunitas Bambu. 


\section{LAMPIRAN I}

\begin{tabular}{|l|l|l|}
\hline \multicolumn{1}{|c|}{ Nama Organisasi } & \multicolumn{1}{|c|}{ Wilayah } & Tahun Pembentukan Organisasi \\
\hline Poetri Mardika & Jakarta & 1912 \\
\hline Keoetamaan Istri & Bandung & 1913 \\
\hline Keradjinan Amai Setia & Kota Gadang Minangkabau & 1914 \\
\hline Wanito Hadi & Jepara & 1915 \\
\hline Prawijatan Wanito & Magelang & 1915 \\
\hline Poerborini & Tegal & 1917 \\
\hline $\begin{array}{l}\text { PIKAT (Pertjintaan Ibu Kepada } \\
\text { Anak Temoeroen) }\end{array}$ & Manado & 1917 \\
\hline Wanito Soesilo & Pemalang & 1918 \\
\hline Wanodjo Oetomo & Yogyakarta & 1920 \\
\hline $\begin{array}{l}\text { Gorontalische Moham-medaan- } \\
\text { she Vrouwenbeweging }\end{array}$ & Gorontalo & 1920 \\
\hline Sarekat Kaoem Iboe Soematra & Bukittinggi & 1920 \\
\hline Kamadjoean Isteri & Jakarta dan Bogor & 1926 \\
\hline Mardi Kamoeliaan & Madiun & 1927 \\
\hline Ina Toeni & Ambon & 1927 \\
\hline Poetri Setia & Manado & 1928 \\
\hline Wanita Sahati & Jakarta & 1928 \\
\hline
\end{tabular}

Sumber: Blackburn, S. (2007). Kongres Perempuan Pertama Tinjauan Ulang. Jakarta: Yayasan Obor Jakarta/ Jakarta- KITLV. 